\title{
Metodología de trazado de corredores ferroviarios de mínimo impacto ambiental. Caso particular: Alta velocidad Huelva (España) - Faro (Portugal)
}

\author{
Methodology for drafting least environmental cost \\ railway corridors. Practical case study: High speed rail \\ route Huelva (Spain) - Faro(Portugal)
}

E. González $^{(*)}$, E. Moreno ${ }^{(*)}$, F. Cabello ${ }^{(*)}$, E. Ivarez ${ }^{(* *)}$

RESUMEN

El trabajo contempla el desarrollo de una metodología de Evaluación Multicriterio para establecer el corredor ferroviario de mínimo impacto ambiental entre Huelva (España) y Faro (Portugal). Este estudio forma parte del proyecto Interreg "Evaluación ambiental estratégica (EAE) de las posibles conexiones ferroviarias (Convencional / Alta Velocidad) Huelva - Algarbe (EAE-FER)" (www.web-rise.eu). La metodología prevé en primer lugar la selección de los factores ambientales que van a intervenir en el modelo y la recogida y homogeneización de la información ambiental existente entre los dos países, así como su posterior implementación en un Sistema de Información Geográfica. A continuación se calculan las superficies de fricción (resistencia al desplazamiento) de los factores seleccionados, y mediante combinación lineal ponderada e introduciendo como restricciones los limitantes se obtiene la superficie final de fricción, a partir de la cual, y junto con los puntos origen y destino es posible obtener el corredor y camino mínimos.

$113-119$

Palabras clave: SIG; evaluación multicriterio; impacto ambiental; corredores; infraestructuras lineales.

\section{SUMMARY}

This work enables the developing of a multi-criteria assessment methodology to find the least environmental cost railway corridor that connects Huelva (Spain) and Faro (Portugal). This paper is part of Interreg Project entitled "Strategical impact assessment (SIA) for the possible railway connections (high speed/conventional) Huelva-Algarve (EAE-FER)" (www.webrise.eu). The approach enables, in the first place, the selection of the environmental factors that will be considered in the model, the homogenization of environmental information from the two different countries, as well as its subsequent implementation in a GIS (Geographical Information System). In the second place cost surfaces are calculated from selected factors, and using a linear weighted combination and introducing the limited factors as a restriction, the final friction surface is obtained, which in conjunction with the points of origin and destination, it is possible to obtain the least- environmental-cost corridor and alignment.

Keywords: GIS; multicriteria assessment; environmental impact; corridors; linear infrastructure.

\footnotetext{
(*) Universidad de Huelva (España).

${ }^{(* *)}$ Consejería de Medio Ambiente. Junta de Andalucía (España).

Persona de contacto/Corresponding author: algarra@uhu.es (E. González).
} 


\section{INTRODUCCIÓN}

La planificación de corredores de transporte es una tarea compleja que aglutina muchos interesados y expertos que normalmente tienen opiniones y expectativas opuestas, que según (1) incrementan la complejidad en la toma de decisiones. Los proyectos de transporte son normalmente complejos y manejan una gran cantidad de información. Los Sistemas de Información Geográfica (SIG) se han utilizado satisfactoriamente para manejar la información y los procesos de toma de decisión de este tipo de proyectos (2). Los SIG permiten almacenar y procesar gran cantidad de información territorial y proporcionan un gran número de funciones analíticas para analizar dicha información y generar resultados. Estas utilidades han sido usadas en gran número de proyectos de transporte especialmente para identificar la ruta de mínimo impacto. (3) utilizan el SIG y un sistema multicriterio para evaluar una serie de trazados de transporte basándose en topografía, núcleos urbanos, aspectos medioambientales y de diseño del trazado con especial énfasis en la caracterización geotécnica. Aproximaciones similares han sido utilizadas para identificar el trazado que minimice el impacto ambiental sobre la fauna, la flora, suelos, agua, aire y población (4). HDR Engineering utiliza numerosas variables incluyendo sitios históricos, zonas húmedas, cruces de arroyos, los yacimientos históricos y el modelo digital del terreno para localizar los corredores más adecuados a través de las Montañas de los Apalaches del Norte de Georgia (5). (6) aplica métodos multicriterio y SIG para la selección del corredor de una autopista interestatal en el sureste de los Estados Unidos. Se trata de una metodología SIG de planificación de corredores Ilamada Analytic Minimum Impedance Surface (AMIS). AMIS resulta de la unión de un análisis espacial riguroso mediante un SIG raster (ArcView) con la metodología de apoyo a la decisión Analytic Hierarchy Process o AHP. AMIS combina variables como el desarrollo económico y la mejora de la conectividad con otras variables territoriales como espacios protegidos, humedales, endemismos, etc. (7) ponen de manifiesto la eficacia de obtener corredores de transporte utilizando un sistema de decisión multicriterio (Multi Criteria Decision Making) integrado en un SIG, ya que de esta manera se consigue una solución de equilibrio entre los objetivos económicos, ambientales y sociales en la fase de planificación. (8) han creado un modelo para definir la mejor localización en el territorio de nuevos proyectos de infraestructuras viarias. La metodología prevé la recogida e implementación, dentro de un sistema de información territorial, de un amplio abanico de datos, posteriormente interpretados y reconducidos a síntesis mediante la aplicación de una serie de indicadores específicos, los cuales se incorporan posteriormente mediante la aplicación de técnicas de análisis multicriterio para definir un índice de evaluación sintético capaz de estimar de forma correlacionada la sensibilidad del territorio ante la introducción de nuevas infraestructuras viarias.

(9) sugieren que, dada la complejidad de los datos ambientales y la necesidad de tener en cuenta diferentes factores y opiniones, resultan de gran utilidad metodologías que tengan en cuenta la valoración individual de cada factor (valoración inter-factores), así como una posterior valoración global (valoración intra-factores). En este contexto (10) explicó, ilustrándolo con cinco ejemplos de aplicación, como un MCDM (Multi Criteria Decision Making) basado en un SIG puede mejorar la eficiencia de la planificación del transporte. Los MCDM hacen posible la aplicación y modelización de las preferencias de los interesados y ofrece la oportunidad de mejorar la coordinación y colaboración entre las administraciones, organizaciones y ciudadanos afectados.

Los MCDM han proporcionado resultados positivos en términos de planificación de transporte desde hace quince años (10-13). Sin embargo, al menos dos aspectos necesitan ser mejorados:

1. Un sistema automatizado de ayuda a la decisión que permita la integración para cada factor de los diversos valores proporcionados por los expertos y que trabaje con información espacial

2. Una metodología para obtener el peso que cada factor tiene en el impacto final utilizando preferentemente un proceso iterativo que permita una cierta convergencia de las opiniones de los expertos.

En este sentido, (14) presentan una aproximación práctica basada en una adaptación del método MCDM de análisis jerárquico Analytical Hierarchy Process (AHP) (15). El esquema jerárquico está desarrollado en dos niveles. En un primer nivel se seleccionan factores que se valoran según un criterio, generándose como consecuencia los denominados "escenarios simples". En un segundo nivel se ponderan los factores según las opiniones de expertos y preferencias de los interesados, y se combinan los escenarios simples ponderados por su peso generándose como resultado la superficie de coste acumulativa, la cual se usa como referencia para calcular el corredor de menor coste medioambiental. Los datos e información utilizados por Nobrega son el resultado de un proyecto de investigación de la circunvalación I-269 propuesta en Memphis. 
Siguiendo la misma línea, se desarrolla en el presente artículo una metodología para establecer el corredor ferroviario de mínimo impacto ambiental entre Huelva (España) y Faro (Portugal). Este estudio forma parte del proyecto Interreg "Evaluación ambiental estratégica (EAE) de las posibles conexiones ferroviarias (Convencional / Alta Velocidad) Huelva - Algarbe (EAE-FER)" (www.web-rise.eu), que la Universidad de Huelva está realizando en colaboración con la Universidad de Faro.

\section{ANTECEDENTES}

Portugal y España acordaron en la XIX Cumbre Luso-Española celebrada en Figueira da Foz en octubre de 2003 la construcción de cuatro líneas de alta velocidad entre VigoOporto (2008), Madrid-Lisboa (2010) y, en una segunda fase, conexiones entre Salamanca-Aveiro (2015) y Huelva-Faro (2018). En esta Cumbre se destacó la necesidad de mejorar las infraestructuras de transporte comunes para combatir las desventajas del carácter periférico que, en el contexto peninsular, tienen las comarcas fronterizas de Portugal y Andalucía, por ello, se considera que una de las medidas más relevantes en ese sentido sería la construcción del tren de alta velocidad Huelva-Faro.

En este contexto se plantea este trabajo cuyo primordial objetivo es encontrar las conexiones ferroviarias Huelva-Faro más óptimas desde el punto de vista ambiental.

\section{DESCRIPCIÓN DE LA ZONA}

La zona de estudio se encuentra situada entre las poblaciones de Huelva (España) y Faro (Portugal), a $100 \mathrm{~km}$ en línea recta, y se extiende $50 \mathrm{~km}$ desde la línea de costa hacia el interior. A continuación se recogen las principales características de la zona:

- Estamos ante un territorio que presenta una gran riqueza metalogénica. Este hecho ha propiciado que desde tiempos inmemoriales haya sido intensamente explotado por la minería, actividad que ha dejado una enorme impronta en el paisaje. Aún así a lo largo de todo el territorio de estudio son numerosas las zonas que presentan algún tipo de protección. En la parte de Huelva nos encontramos con las Marismas del Odiel (Paraje Natural), Marismas del Río Piedras y Flecha del Rompido (Paraje Natural), Marismas de Isla Cristina (Paraje Natural), Corredor ecológico del río Tinto (Paraje Natural), Andévalo occidental (Sitio de Interés Comunitario) y el río Guadiana. En la parte portuguesa encontramos Ria Formosa (Reserva Natural), Vale do Guadiana
(Parque Natural), Castro Verde (Paraje Natural), Sapais do Castro Marim (Reserva Natural) y Caldeirao (Sitio de Interes Comunitario) (Figura 1).

- Las características geomorfológicas, topográficas así como sus condiciones climáticas dan lugar a que el territorio aparezca surcado de un número considerable de cursos de agua, muchos de ellos con caudales muy copiosos en unas épocas del año y completamente secos en otras (Figura 2). Estos ríos presentan en sus orillas una variada vegetación según discurra su lecho, apareciendo en algunos casos bosques de ribera de gran valor ecológico en los que aparecen fresnos, alisos y sotos de gran diversidad. El río más importante que atraviesa la zona es el Guadiana. En su tramo final presenta un caudal abundante y está sujeto a la influencia mareal, hecho que queda reflejado en las formaciones vegetales que lo acompañan, las más características son los cañaverales y carrizales.
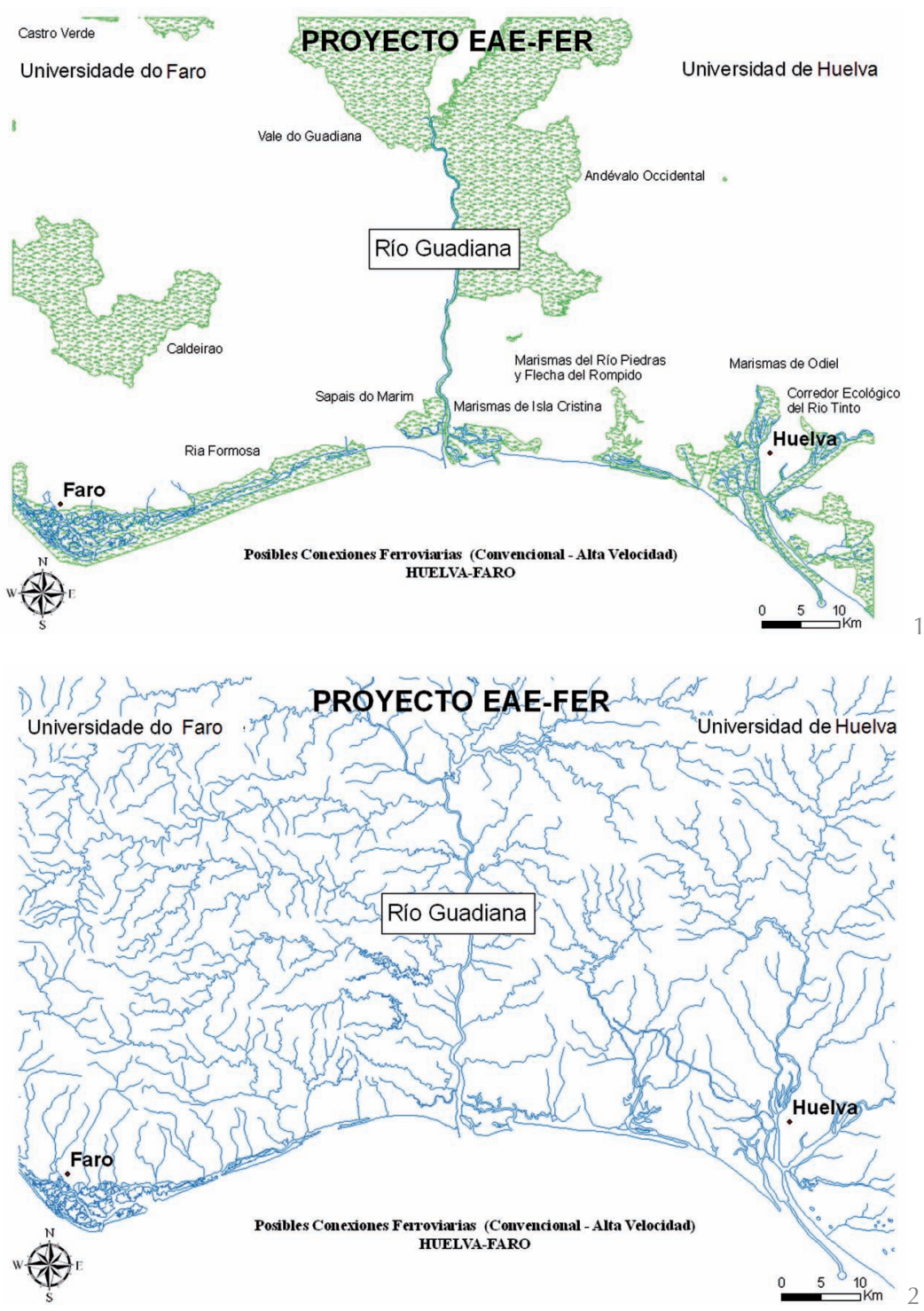


\section{METODOLOGÍA}

Para establecer el corredor de mínimo impacto se ha seguido un proceso que consta de los siguientes pasos:

1. Selección de factores y recopilación de la información ambiental disponible para la zona de estudio (España y Portugal).

2. Homogeneización de la información ambiental y adaptación a un formato cartográfico normalizado.

3. Elección del Sistema de Información Geográfica y la proyección cartográfica.

4. Diseño y aplicación del modelo de cálculo del corredor y trazado de mínimo impacto.

5. Validación del modelo.

\subsection{Selección de factores y recopilación de toda la información ambiental disponible para la zona de España y la zona de Portugal}

El problema en este punto surge ante la imposibilidad de encontrar información disponible para todo el territorio, al tratarse de dos países distintos. Solo se han podido encontrar para todo el territorio el Mapa de Usos de Suelo Corine Land Cover, ya que éste existe para toda Europa, y el Mapa de Hidrología 1:250.000 de la Península Ibérica. Además, se han recogido los siguientes mapas por separado de ambos países: Mapa de vegetación, Mapa forestal, Red de Carreteras, Caminos, Límites administrativos, Hidrología y Espacios protegidos.

\subsection{Homogeneización de la información ambiental y adaptación a un formato cartográfico normalizado}

Al transcurrir la infraestructura entre dos países gran parte de la cartografía necesaria para el estudio se ha realizado por organismos distintos. Es por tanto necesario homogeneizar la información. Como resultado, se han obtenido seis mapas para todo el territorio:

- Mapa de Hidrología (1:250.000)

- Mapa de Usos de Suelo Corine Land Cover $(1: 100.000)$

- Mapa de Núcleos Urbanos (1:100.000)

- Infraestructuras lineales (1:100.000)

- Mapa de Figuras de Protección (1:25.000)

- Mapa de Patrimonio Cultural (1.100.000).

Al presentarse información digital con distintas escalas, se ha decidido utilizar desde un primer momento la escala mayor de los datos disponibles, al ser un territorio extenso y así evitar los posibles errores que se pueden producir al intentar reducir a esca- las menores. Se ha elegido por tanto como escala de trabajo la 1:250.000.

Los seis mapas comentados anteriormente a escala 1:250.000, en formato raster y con tamaño de celda de 1 ha son los que se han utilizado como partida del modelo de cálculo del corredor de mínimo impacto que se comenta en el apartado 4.4.

En el mundo de los Sistemas de Información Geográfica existen dos aproximaciones básicas a la cuestión de cómo modelizar el espacio, de las que resultan dos modelos de datos: vectorial y raster (16). En el modelo raster el espacio es compartimentado en una serie de elementos discretos por medio de una retícula regular, habitualmente rectangular, compuesta por celdas cuadradas. Cada celda o píxel se identifica por su número de fila y columna. En cuanto a la información temática, a cada celda le corresponde un único valor relativo a la variable que se está representando.

\subsection{Elección del Sistema de Información Geográfica y las proyecciones cartográficas}

Se ha elegido el Sistema de Información Geográfica ArcGIS 9.3 de ESRI (Environmental System Research Institute) al ser uno de los sistemas más flexibles y utilizados a nivel mundial. En cuanto a la proyección se ha empleado la proyección UTM, European Datum 1950 UTM Zone 30N.

\subsection{Diseño y aplicación del modelo de cálculo del corredor y trazado de mínimo impacto ambiental}

Para calcular el camino mínimo entre dos celdas o grupos de celdas es necesario partir previamente de un "mapa de costes". Un tipo de distancias de gran interés en los estudios territoriales son aquellas que se miden en términos de "costes" al atravesar zonas con dificultad de paso variable. Existen distintos tipos de costes: costes de tiempo, costes económicos, impacto sobre el medio, etc (17).

Para calcular los mapas de costes es necesario, además de un mapa con la celda o celdas origen, otro mapa Ilamado superficie de fricción (resistencia al desplazamiento), en el que a cada píxel se le asigna un valor en función de la dificultad para pasar por él. Si existe un área que no puede ser atravesada por constituir una barrera absoluta al movimiento, a las celdas correspondientes a esa área se les debe asignar un valor de fricción tan elevado que en la práctica se comporten como si se tratara de barreras absolutas. 
Obtenida la superficie de fricción, y a partir del mapa con las celdas origen, la ciudad de Huelva en este caso, se calcula el mapa de costes. Para ello, cada paso de una celda a otra se pondera en función del valor que tienen las celdas en la superficie de fricción multiplicando la distancia por el valor de fricción.

Los mapas de costes se emplean a menudo para calcular el camino de coste mínimo entre dos celdas o grupos de celdas (18). El sistema es capaz de encontrar la ruta óptima de forma que se minimicen los costes. El resultado es un conjunto de celdas alineadas que marcan el camino óptimo, de mínimo impacto en este caso.

En la Figura 3 se presenta el esquema de la metodología empleada.

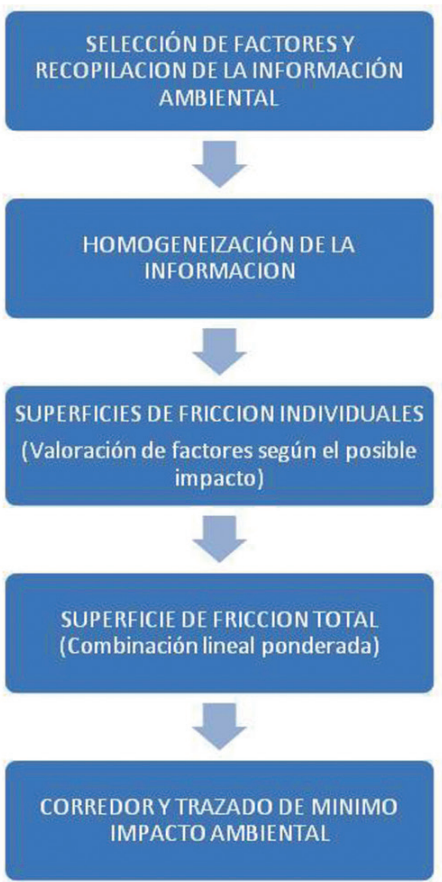

\subsubsection{Cálculo de la superficie de fricción}

Se utilizan cinco factores y cuatro limitantes.

Los factores son:

- Usos de suelo

- Hidrología

- Distancia a figuras de protección

- Distancia a núcleos urbanos

- Distancia a infraestructuras lineales

Los limitantes son:

- Tejido urbano continuo

- Figuras de protección

- Núcleos urbanos

- Patrimonio cultural

El procedimiento a seguir consiste en primer lugar en obtener la superficie de fricción para cada uno de los factores. Para ello se valora cada factor en una escala de 1 a 10 de forma que 1 representa mínima oposición o resistencia al paso de la carretera (mínimo impacto ambiental) y 10 una oposición máxima (máximo impacto ambiental). Los valores de fricción son fricciones relativas a 1 . Una fricción de 2 indica que el paso por esa celda supone doblar el coste base (1). A los limitantes se les da un valor de fricción muy alto (1000) para impedir el paso totalmente.

En segundo lugar se calcula la superficie de fricción total mediante la combinación lineal ponderada de las superficies de fricción de los factores e introduciendo como restricciones los limitantes.

\subsubsection{Valoración de usos de suelo}

La Tabla 1 muestra la valoración de las distintas ocupaciones del suelo del Corine Land Cover de la zona. Como resultado de aplicar dicha valoración se obtiene el mapa de fricción de usos de suelo (vease Figura 4).

Tabla 1. Valoración de usos de suelo

\begin{tabular}{|l|c|}
\hline Ocupación & Valor \\
\hline Escombreras y vertederos & 1 \\
\hline Tierras de labor en secano & 1 \\
\hline Terrenos regados permanentemente & 1 \\
\hline Praderas & 1 \\
\hline Cultivos anuales asociados con cultivos permanentes & 1 \\
\hline Mosaicos de cultivos & 2 \\
\hline Pastizales naturales & 2 \\
\hline Vegetación esclerófila & 2 \\
\hline Viñedos & 3 \\
\hline Frutales & 3 \\
\hline Olivares & 3 \\
\hline Matorral boscoso de transición & 4 \\
\hline Terrenos principalmente agrícola con importantes espacios naturales & 5 \\
\hline Sistemas agroforestales & 5 \\
\hline Zonas quemadas & 6 \\
\hline Láminas de agua & 6 \\
\hline Playas dunas y arenales & 7 \\
\hline Zonas Ilanas intermareales & 7 \\
\hline Lagunas costeras & 7 \\
\hline Bosque de conífera & 8 \\
\hline Salinas & 8 \\
\hline Cursos de agua & 8 \\
\hline Estuarios & 8 \\
\hline Zonas de extracción minera & 9 \\
\hline Bosque mixto & 10 \\
\hline Tejido urbano discontinuo & 10 \\
\hline Zonas industriales o comerciales & 10 \\
\hline Redes viarias, ferroviarias y terrenos asociados & 10 \\
\hline Zonas portuarias & 10 \\
\hline Aeropuertos & 10 \\
\hline Zonas en construcción & 10 \\
\hline Instalaciones deportivas y recreativas & 10 \\
\hline Bosque de Frondosas & \\
\hline Marismas & 100 \\
\hline Tejido urbano continuo & 2 \\
\hline & 2 \\
\hline
\end{tabular}




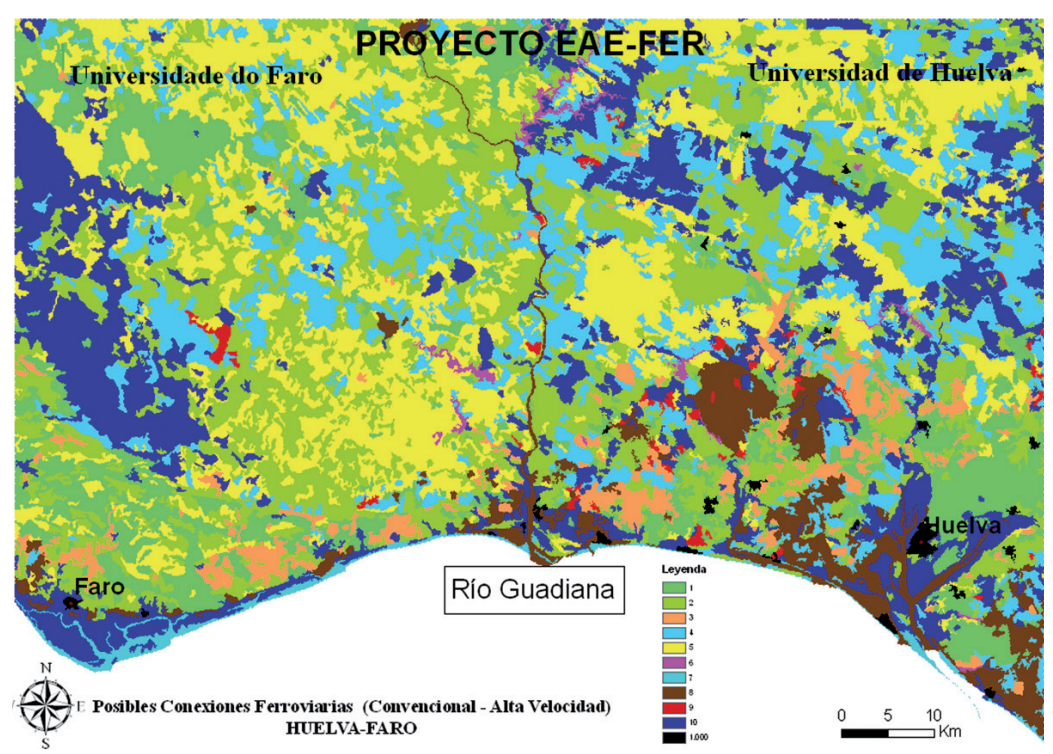

4. Mapa de fricción de usos de suelo y limitante.

5. Fricción distancia a figuras de protección y limitante.

6. Fricción distancia a nucleos urbanos y limitante.

\subsubsection{Valoración de hidrología}

Para valorar la hidrología se ha tenido en cuenta que los cursos de agua puedan ser atravesados por el trazado de la vía pero sin que ésta discurra por encima de ellos durante mucho recorrido. Para conseguir esto se ha utilizado un valor de 10 en los tramos de agua.

\subsubsection{Valoración de zonas de protección}

Son numerosas las figuras de protección empleadas por ambos países. En el caso de España y Portugal las figuras que presentan similares características de protección son las siguientes: Paraje Natural, Parque Natural, ZEPA (Zona de Especial Protección para Aves), ZIC (Zonas de Importancia Comunitaria), Sitios de Interés Comunitario y Reserva Natural, si bien en Portugal existe la figura de protección de las reservas agrícolas, la cual se ha considerado bajo el mismo criterio para el análisis.
Para esta cartografía se ha realizado un buffer alrededor de los polígonos que delimitan las figuras de protección de 500 m; con lo que se consigue que el trazado no pase a menos de esta distancia de las zonas protegidas. Las figuras de protección se han valorado con un valor limitante de 1000 y los buffer un valor de 10. Fuera del buffer se da el valor de 1 (mínimo impacto) (Figura 5).

\subsubsection{Valoración de núcleos urbanos}

Con esta cartografía se ha realizado un proceso similar al explicado anteriormente. Se crea un buffer de $500 \mathrm{~m}$ alrededor de los núcleos urbanos y se le da un valor de 10, fuera del buffer el valor será 1. Los núcleos tendrán también valor limitante de 1000 (Figura 6).

\subsubsection{Valoración de Infraestructuras lineales}

En este mapa se tienen en cuenta todos los elementos lineales que hay en la zona, a excepción de los tendidos eléctricos. Es el caso de Autovías, Carreteras y líneas de ferrocarril ya existentes. Se ha realizado un buffer de $50 \mathrm{~m}$ a lo largo de estas infraestructuras con un valor de 10 para intentar que el trazado cruce el menor número de veces posible por alguna de estas infraestructuras.

\subsubsection{Valoración de Patrimonio Cultural}

Las zonas de Patrimonio cultural: Zonas Arqueológicas, Monumentos y Conjuntos Históricos se han valorado con un limitante de 1000 por lo que el trazado no pasará por encima de ellas.

\subsubsection{Cálculo de la superficie de fricción final}

Se calcula mediante la combinación lineal ponderada de las superficies de fricción de los factores e introduciendo como restric-
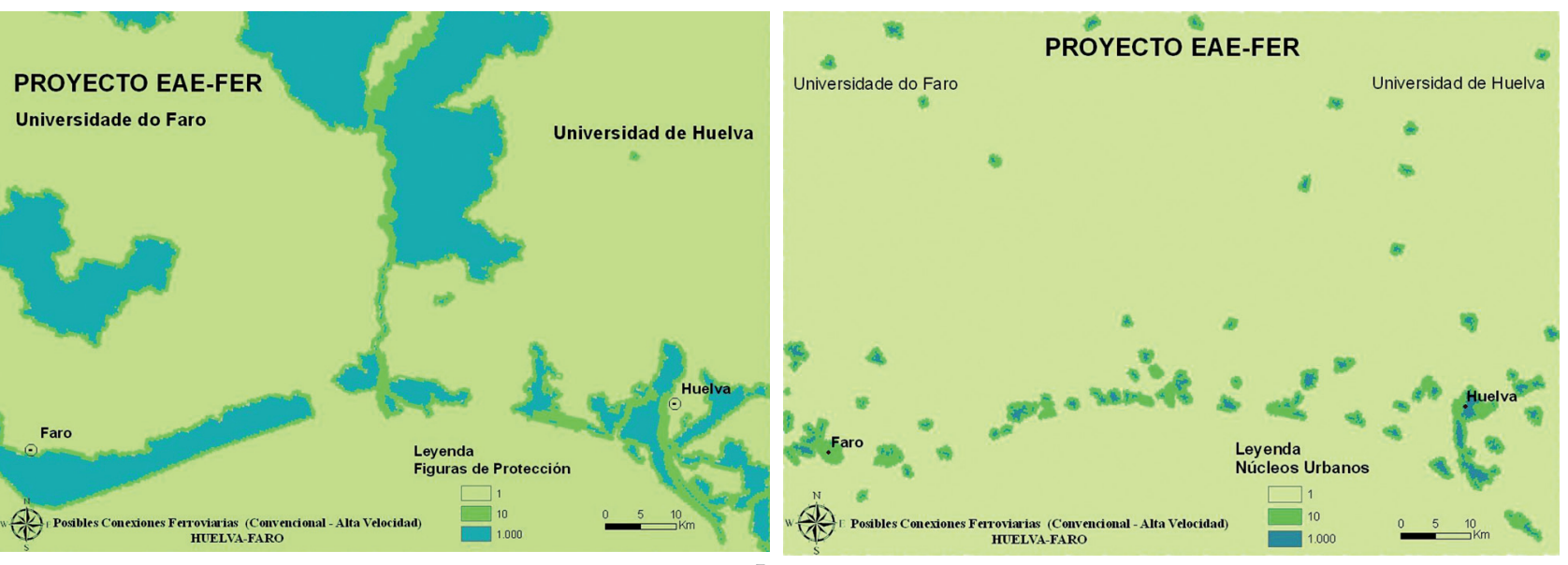
ciones los limitantes. Se obtiene como resultado un mapa que presenta valoraciones de 1 a 10, y los limitantes valor 1000, con lo que se asegura que el corredor no pase por estas zonas (Figura 7).

\subsubsection{Cálculo del corredor y camino mínimos}

A partir del mapa de costes, y con las celdas destino (Faro), es posible identificar "corredores de mínimo impacto" sobre los cuales ha de superponerse la alternativa de mínimo impacto ambiental. Para calcular el corredor el sistema busca sobre el mapa de costes los valores más bajos de las celdas comprendidas entre el punto origen y destino. La zona que aparece de color marrón oscuro en la Figura 8 es el corredor por donde preferiblemente debería transcurrir la infraestructura.

A partir del mapa de costes, y con la celdas destino (Faro), también es posible identifi- car el camino de mínimo impacto o camino mínimo que enlazará las celdas origen y destino. Este camino mínimo será el posible trazado de la futura vía férrea que unirá las poblaciones de Huelva y Faro (Figura 8).

\subsection{Validación del modelo}

Se han realizado estudios de campo para comprobar el trazado en las posibles zonas más frágiles identificadas sobre una ortofoto.

En una primera fase, y una vez localizadas las 23 teselas que pueden ser importantes, se han hecho los estudios de campo de las teselas desde Huelva hasta la frontera. Hasta la frontera se han localizado 12 teselas (Figura 9). Ninguna de ellas presenta problemas excepto la tesela número 6 . Se trata de un curso de agua que presenta en sus márgenes vegetación de ribera ( $E u$ calyptus globulus, Pinus pinea, Salix sp., Olea europaea var. sylvestris, Arundo do-
7. Cálculo de la superficie de fricción final.

8. Corredor y trazado de mínimo impacto entre Huelva y Faro.

9. Zonas importantes hasta la frontera.
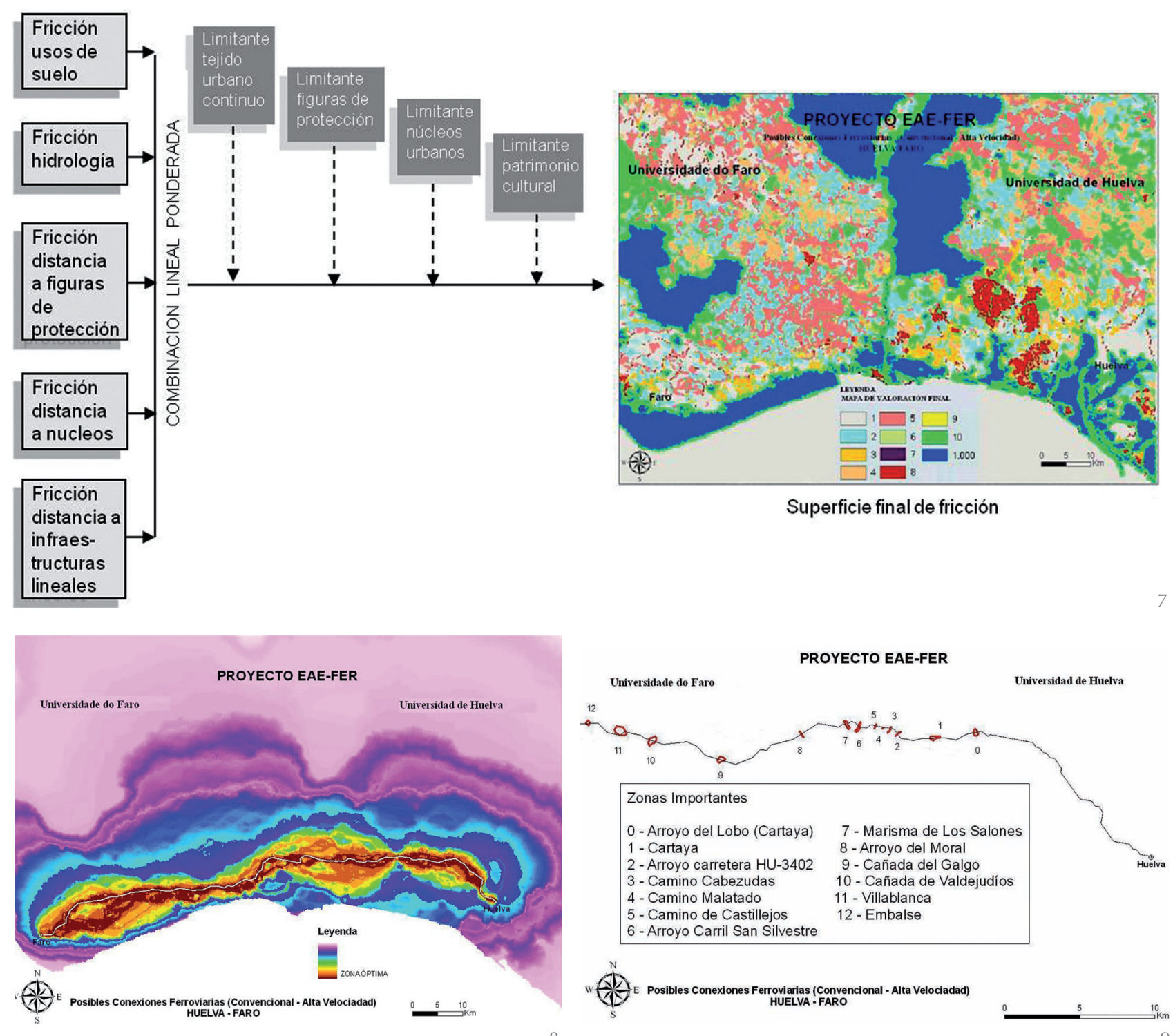
10. Tesela $n^{\circ}$ 6. Arroyo del Carril San Silvestre (Cartaya)

11. Modificación del trazado de la vía sobre la ortofoto.

12a. Paso del trazado por Marismas del Odiel.

12 b. Paso por fuera de las marismas, por zonas de cultivo.

13. Trazado de la futura vía férrea con las dos modificaciones. nax, Phragmites australis, Tamarix sp., Nerium oleander), la cual, se debería intentar alterar lo menos posible; debido a esto se procede a modificar sobre la ortofoto el trazado de la vía a la zona más estrecha del curso de agua (Figuras 10 y 11).

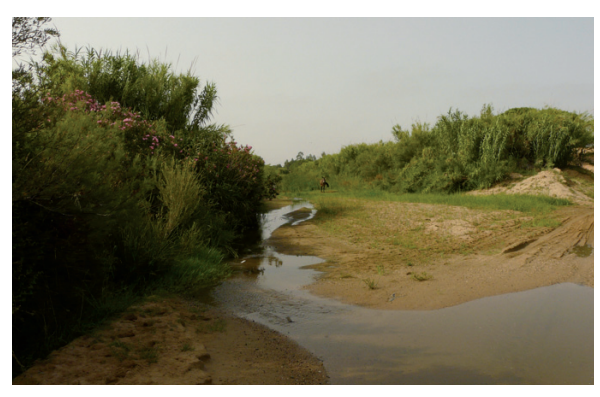

10

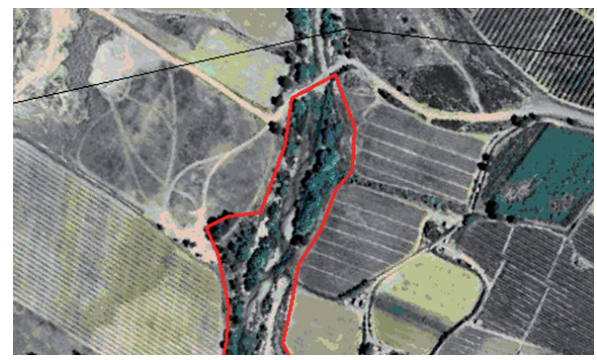

11

Otro problema que se ha encontrado, es que el programa establece el trazado de la vía paralelo al actual puente que cruza las Marismas del Odiel, uniendo Huelva con Punta Umbría. El problema surge porque cruza el Paraje Natural Marismas del Odiel por una zona muy estrecha, inferior a 1 ha, de forma, que al ser una mínima parte de la superficie de la celdilla el sistema le ha asignado valor no restrictivo. Como solución, se procede a modificar el trazado de la vía desviándolo por una zona de cultivos paralela a la carretera que une Huelva con Gibraleón (N-441), hasta unirse con el corredor de mínimo impacto.

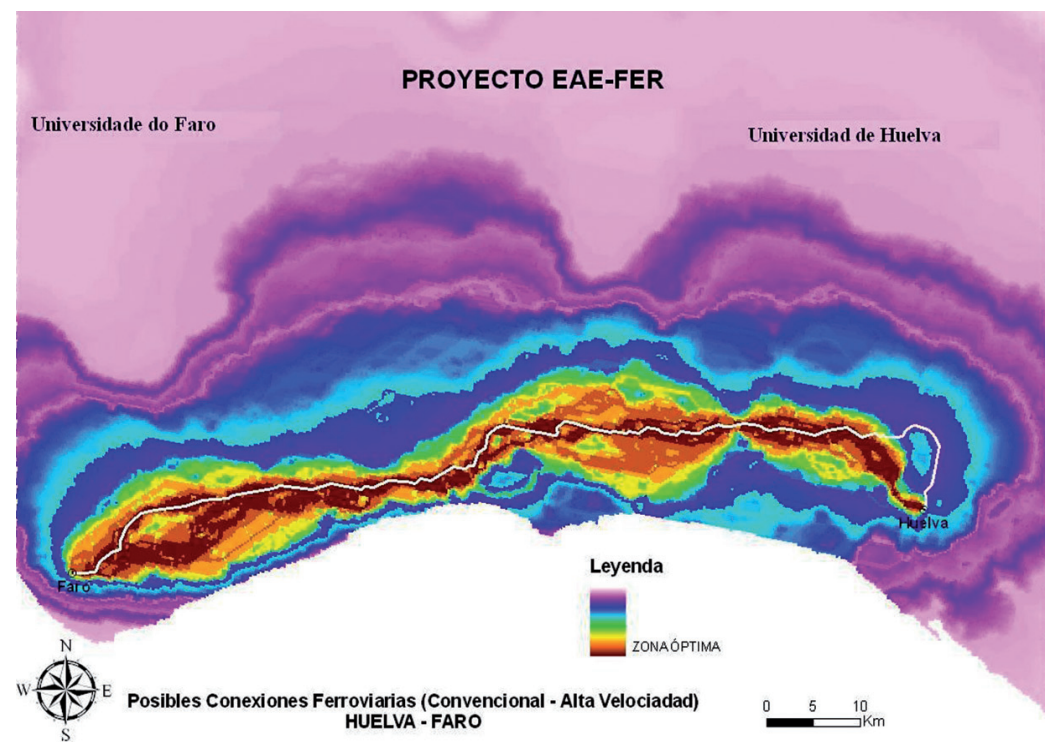

13
Con esta modificación se consigue que el corredor no pase por el Paraje Natural de Marismas del Odiel, aunque como resultado se obtenga un trazado más largo ( $\mathrm{Fi}$ gura $12 \mathrm{a}$ y $12 \mathrm{~b}$ ).

En la Figura 13 se observa el trazado definitivo de la vía férrea resultado de las dos modificaciones realizadas.

\section{RESULTADOS}

1. En este tipo de estudios, y en territorios transfronterizos, la primera tarea es homogeneizar la cartografía ambiental existente en ambos territorios. De este modo, el primer resultado de este proyecto ha sido la cartografía ambiental homogeneizada para Huelva (España)- Algarve (Portugal), la cual puede ser utilizada en futuros proyectos de investigación

2. El resultado final de este modelo es el trazado y el corredor de mínimo impacto. La ventaja del corredor es que permite un grado de libertad al decisor ya que en muchas ocasiones no es posible respetar en su totalidad el trazado de mínimo impacto obtenido debido a factores exógenos al estudio como las consideraciones políticas, técnicas o económicas.

3. La utilización de la "superficie de fricción" o "resistencia al desplazamiento" asegura que el tramo de ferrocarril no discurra por zonas que presenten algún tipo de protección, como es el caso de los parques o parajes naturales; también se consigue que no se vean afectados núcleos urbanos, ni sus inmediaciones, y que sean atravesadas el menor número de veces posible las zonas de alto valor ecológico, infraestructuras lineales y los cursos de agua.

4. En el proceso de validación del modelo se ha comprobado que los resultados obtenidos son globalmente satisfactorios, en concreto más del noventa y cinco por ciento del trazado se ha validado satisfactoriamente. Únicamente en dos situaciones puntuales se han encontrado problemas debido a la escala de trabajo utilizada. En estos dos puntos se ha modificado el trazado.

5. Otro resultado importante de este trabajo es el diseño de una sistemática de trabajo, en la que se definen unas fases previas a la aplicación del modelo multicriterio en el SIG. Estas fases son: selección de factores ambientales, y recopilación y homogeneización de la información ambiental.

\section{CONCLUSIONES}

Los SIG y el uso de las metodologías de Evaluación Multicriterio, queda compro- 
bado que son una herramienta de alto potencial a la hora de diseñar corredores reales para cualquier tipo de infraestructura lineal. Disponer de estos corredores, permite minimizar en gran medida el impacto ambiental que pueden Ilegar a generar, introduciendo la consideración ambiental desde un primer momento del diseño de la infraestructura.El modelo desarrollado en este trabajo, al estar integrado en un SIG, permite introducir modificaciones o actualizar la información en el momento que se desee, así como ser exportable a otros territorios. Aunque, como se ha comentado en resultados, el modelo da globalmente unos resultados muy satisfactorios, se recomienda realizar una validación en campo en las zonas más frágiles.

\section{BIBLIOGRAFÍA}

(1) Thabrew, L.; Wiek, A.; Ries, R.: "Environmental decision making in multi-stakeholder contexts: applicability on life cycle thinking in developing planning and implementation", Journal of Cleaner Production, vol. 17 (2009), pp. 67-76.

(2) Frerichs W. N., West J. R.: "Using GIS to streamline and improve highway planning and design", Roadway Design, CE NEWS online ( november, 1998).

(3) Sadek, S.; Bedran, M.; Kaysi, I.: "GIS platform for multi-criteria evaluation of route alignments", Journal of Transportation Engineering, vol. 125, $\mathrm{n}^{\circ} 2$ (March/April 1999), pp. 144-148.

(4) Zura, M.; Lipar, P.: The road and traffic environmental impact statement and optimal room layout selection, in 15th Annual Environmental Systems Research Institute User Conference Proceedings (1995). Environmental Systems Research Institute. Redlands CA.

(5) Gilbrook, M. J.: Finding the Appalachian scenic corridor in the 18th, Annual ESRI International User Conference Proceedings (1998). Environmental Systems Research Institute.

(6) Bailey, K.: AMIS: Development and Application of a GIS/Multicriteria Corridor Evaluation Methodology, Proceedings of the Map Asia 2003 Conference, 2003.

(7) Sharifi, M. A.; Beorboom, L.; Shamsudin, K. B.; Veeramuthu, L.: Spatial multiple criteria decision analysis in integrated planning for public transportation and land use development study in Klang Valley, Malaysia, Proceedings of the ISPRS Technical Commisision II Symposyum, Vienna (2006), pp. 85-91.

(8) Neri, M.; Menconi,M. E.; Vizzari, M.; Vincenzo G. G. Mennella: "Propuesta de una nueva metodología para la ubicación de infraestructuras viarias ambientalmente sostenibles. Aplicación en el tramo viario de la pedemontana Fabriano-Muccia", Informes de la Construcción, vol. 62, no 517 (enero-marzo 2010), pp.101-112. doi:10.3989/ ic.09.043.

(9) O'Hara, C. G., Davis, A. A.; Kleiss, B. A.: "A decision support system for prioritizing forested wetland restoration in the Yazoo Backwater Area, Mississippi", working paper, Water Resources Investigation Report 00-4199, (2000). United States Geological Service, Pearl ,MS

(10) Saaty, T. L.: "Transport planning with multiple criteria: the analytic hierarchy process applications and progress review", Journal of Advanced Transportation, vol. 29, $\mathrm{n}^{\circ} 1$ (1995), pp. 81-126.

(11) Piantanakulchai, M.; Saengkhao N.: "Evaluation of Alternatives in Transportation Planning Using Multi-Stakeholders Multi-Objectives AHP Modeling", Proceedings of the Eastern Asia Society forTransportation Studies, vol. 4 (2003), pp. 1613-1628-

(12) Huang, B.; Cheu, R. L.; Liew, Y. S.: "GIS-AHP model for HAZMAT routing with security considerations", Proceedings of the IEEE 6th International Conference on Intelligent Transportation Systems (October 2003), Shanghai, China.

(13) Mongkut, P.; Saengkhao, N.: "Evaluation of alternatives in transportation planning using multi-stakeholders multi-objectives AHP modeling", Proceedings of the Eastern Asia Society for Transportation Studies, Fukuoka, vol. 4 (2003), pp. 1613-28.

(14) Nobrega, R. A. A.; O'Hara, C. G.; Sadasivuni, R.; Dumas, J.: “Bridging decision-making process and environmental needs in corridor planning", Management of Environmental Quality, vol. 20, no 6 (2009), pp 622-637. doi: 10.1108/14777830910990744.

(15) Saaty, T. L.: The Analytic Hierarchy Process, NY, McGraw Hill,1980.

(16) Bosque, J.: Sistemas de Información Geográfica, Ediciones Rialp, S.A., Madrid, 2000.

(17) Gutierrez, J.; Gould, M.: SIG: Sistemas de Información Geográfica, ed. Síntesis, S.A., Madrid, 1994.

(18) Gutiérrez, J.; Monzón, A.; Pinéro, J. M.: "Accessibility, network efficiency, and transport infrastructure planning", Environment and planning A, vol. 30, no 8 (1998), pp. 13371350. doi:10.1068/a301337 